\title{
ENHANCED OXYGEN TRANSPORT IN FISH GILLS - FLOW MEASUREMENTS IN A MODEL
}

\author{
U. KERTZSCHER, L. GOUBERGRITS, U. DOLL, G. GABEL \& K. AFFELD \\ Biofluid Mechanics Laboratory, Charité-Universitätsmedizin Berlin, Germany.
}

\section{ABSTRACT}

Fish are able to extract oxygen from water effectively and with low energy consumption. In order to understand this trait, we investigated the flow in a fish gill model. We performed particle image velocimetry measurements on an enlarged simplified model of a fish gill. Two fluid models were used in the experiments: a one-phase and a two-phase flow, the latter of which models blood flow. The local hematocrit value distribution was investigated for the two-phase flow. In addition, the flow was visualized by dye injection for both fluid models. It was concluded from the results that the effective gas exchange is due to an enhanced transversal exchange within the gill with a two-phase flow, a deformation of the erythrocytes, and a local increase in hematocrit.

Keywords: energy consumption, fish, gas exchange, gill, oxygen, oxygenator, particle image velocimetry.

\section{INTRODUCTION}

Vertebrates that use lung respiration obtain oxygen from the air. The oxygen content in air is quite high, about $20 \%$. The oxygen uptake of humans during exercise can be as high as $4320 \mathrm{mg} \mathrm{O}_{2} / \mathrm{min}$. Since the area available for the oxygen exchange is approximately $100 \mathrm{~m}^{2}$, the oxygen exchange per square meter is $43.2 \mathrm{mg} \mathrm{O} / \mathrm{min}$ [1].

In comparison, if we consider the circumstances for an agile fish, such as a trout, we find the following values: The oxygen uptake during exercise is $9.79 \mathrm{mg} \mathrm{O} / \mathrm{min}$ and the exchange area is $0.15 \mathrm{~m}^{2}$ [2]. This results in an oxygen exchange per square meter of $65.28 \mathrm{mg} \mathrm{O} / \mathrm{min}, 50 \%$ higher than in humans. This may not be surprising as the trout is agile, smaller than humans and therefore has a higher energy consumption per volume unit. What may be surprising is that trout reach this high-density oxygen flow in water. In air the oxygen content is $200 \mathrm{ml}$ per liter, in aerated water only $7 \mathrm{ml}$ per liter. Even if you consider that in aerated water and in the air immediately above, the same oxygen partial pressure prevails and therefore the driving force for the diffusion is the same, the conditions for the trout are disadvantageous. Since the oxygen content in water is low, the oxygen partial pressure decreases quickly when oxygen diffuses from water to blood. The fish always has to bring fresh water in contact with its gills. The fish solves this problem with either dynamic pressure at high swimming velocities or the oral cavity pump at lower velocities.

The energy consumption for the oxygen mass transfer in fish is very low. For example, a tench with a mass of $150 \mathrm{~g}$ needs a pressure difference of only $7.4 \mathrm{~Pa}$ (equals $0.75 \mathrm{~mm}$ water height) to maintain a water flow of $1.5 \mathrm{ml} / \mathrm{s}$ through the gills [1]. With this water flow, a tench obtains an oxygen mass flow of $0.5 \mathrm{mg} / \mathrm{min}$ [2]. The pressure loss on the blood side in bony fish is about $1330 \mathrm{~Pa}$ and the blood flow is $15 \mathrm{ml} /(\mathrm{kg} \cdot \mathrm{min})$ [1]. For a tench with a mass of $150 \mathrm{~g}$ this means $2.25 \mathrm{ml} / \mathrm{min}$. Therefore, the required energy to uptake $1 \mathrm{~g}$ of oxygen is $6.4 \mathrm{Ws}$.

Let us now consider the conditions for humans: the pressure loss on the blood side is about $1330 \mathrm{~Pa}$, the blood flow is $5 \mathrm{l} / \mathrm{min}$ and the oxygen uptake is $275 \mathrm{mg} / \mathrm{min}$. This means the required energy is $24 \mathrm{Ws}$ per gram oxygen, if the energy need on the gas side is neglected.

Finally, we can calculate the energy needed for an optimized technical gas exchanger, an oxygenator. An oxygenator from Medtronic (Trillium ${ }^{\circledR}$ Affinity ${ }^{\circledR}$ NT) with a blood flow rate of $41 / \mathrm{min}$ has an oxygen uptake of $359 \mathrm{mg} / \mathrm{min}$ and a pressure loss on the blood side of $5.6 \mathrm{kPa}$ (Medtronic [3]). 
Table 1: Energy consumption for the mass transfer of $1 \mathrm{~g}$ of oxygen in tench, human, and an oxygenator.

\begin{tabular}{|c|c|c|c|}
\hline & $\begin{array}{c}\text { Energy consumption } \\
\text { (non-blood side) } \\
\left(\mathrm{Ws} / \mathrm{g} \mathrm{O}_{2}\right)\end{array}$ & $\begin{array}{c}\text { Energy consumption } \\
\text { (blood side) } \\
\left(\mathrm{Ws} / \mathrm{g} \mathrm{O}_{2}\right) \\
\end{array}$ & 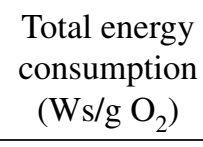 \\
\hline Tench & 1.16 & 5.25 & 6.41 \\
\hline Human & Neglected & 24 & 24 \\
\hline Oxygenator & Neglected & 155 & 155 \\
\hline
\end{tabular}
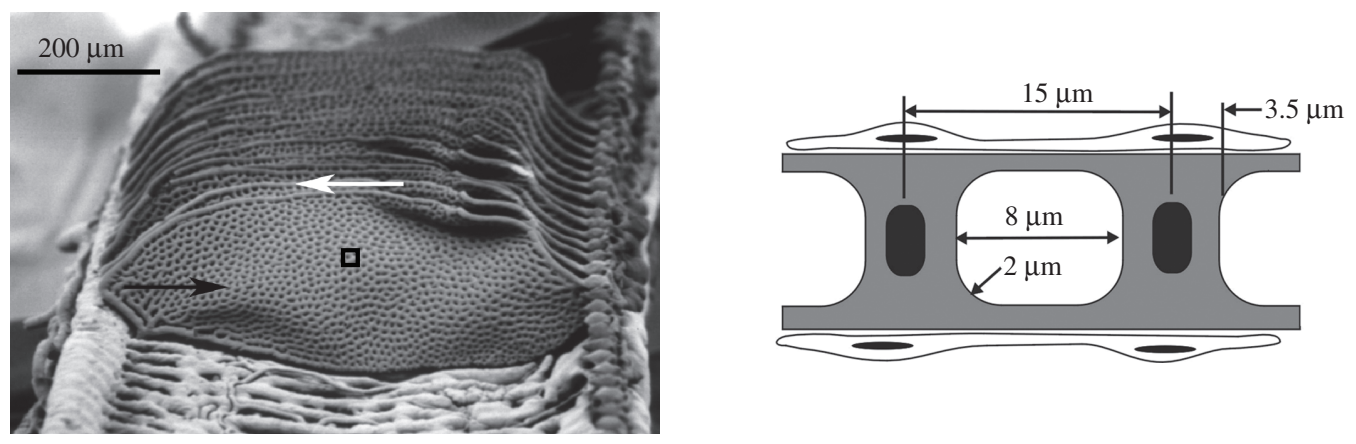

Figure 1: Morphology of a trout gill filament lamella [4, 5]. On the left is a photograph of a fish gill filament with some lamellae. The black arrow shows the direction of the blood flow, the white arrow shows the direction of the water flow. The black square indicates the region of the schematic geometry, which can be seen on the right-hand side.

Therefore, the required energy is $62 \mathrm{Ws}$ per gram oxygen if again the pressure loss on the gas side is neglected. The pressure loss of the heat exchanger is included as part of the calculated energy consumption, but this is very low according to Medtronic.

These considerations are summarized in Table 1. The values in Table 1 raise the question: "Why is the mass exchanger in fish so energy efficient?" Knowledge concerning this could be helpful for the designing of mass or heat exchangers. The lack of an energy efficient mass exchanger is, especially for artificial lungs, a drawback which prevents the development of an implantable oxygenator.

The aim of this paper was to shed light on the effectiveness and efficiency of the gas exchange in fish gills. We propose the hypothesis that the effectiveness of the fish gills is caused by favorable blood flow as a result of gill geometry. Based on this hypothesis, we studied experimentally the flow in the model of a fish gill. Due to the incomplete information available for the trout concerning energy consumption and other data, it was necessary to supplement this with data from the tench.

\section{METHOD}

As a base for the investigations of flow in fish gills, the morphology of trout gill filament lamellae was determined using literature ([4-6]; see Fig. 1). The lamellae consist of two membranes which are sealed along the edges and are connected to each other by pillars throughout the rest of the channel. The blood flows from the inlet into the lamella, the first section of which is similar to a diffuser (Fig. 1, left). This is followed by a region with a more or less constant cross section. Near the outlet, 


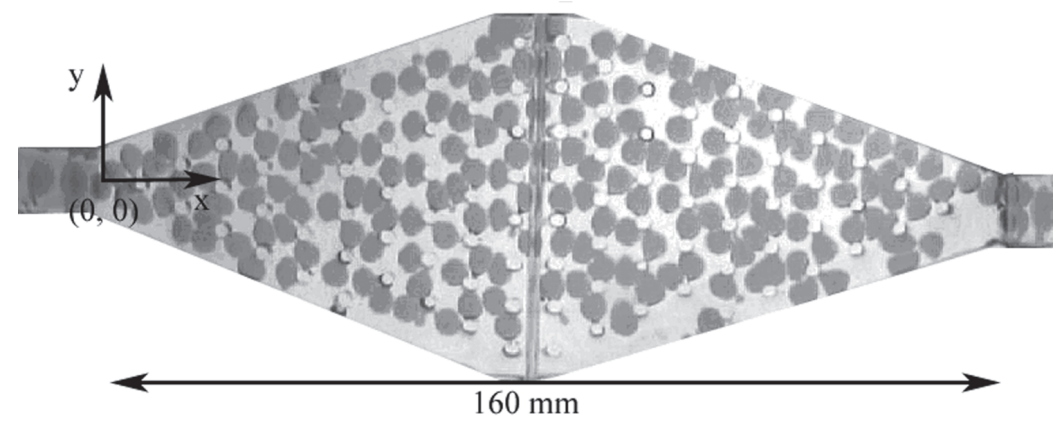

Figure 2: Enlarged model of a fish gill filament lamella with a two-phase flow. The flow is from left to right.

the cross section decreases. The length of the trout lamella is about $800 \mu \mathrm{m}$. The inlet and outlet diameters of the lamella are approximately $20 \mu \mathrm{m}$. The lamella channel size increases from the inlet up to $300 \mu \mathrm{m}$ at the maximum width in the middle of the lamella. The height of the inner lamella channel is constant throughout the lamellae and equal to $7 \mu \mathrm{m}$.

The membranes of the lamellae are connected by collagen pillar cells, which presumably provide structural support against the distending vascular pressure. The diameter of these pillar cells is $7 \mu \mathrm{m}$ and the mean distance between the pillar cells is $15 \mu \mathrm{m}$ (see Fig. 1, right). Since the mean physiological size of elliptical fish blood cells is $10.6 \mu \mathrm{m} \times 7.4 \mu \mathrm{m}$ [7], they are deformed when they pass between the lamellae. The water flows between the lamellae along the outside of both membranes. The flow direction of blood and water is indicated by arrows in Fig. 1.

For a detailed investigation of the flow inside a fish gill filament lamella, a simplified and approximately 500 times enlarged polyvinylchloride (PVC) model of a lamella was manufactured by vacuum forming (see Fig. 2). The geometry of the simplified model was first generated with the help of the 3D CAD program SolidWorks (SolidWorks Corp., USA) and was then used for the fabrication of the form by Metapor BF100Al (Portec AG, Switzerland) with a milling machine. In order to obtain a shorter model, only the inlet and outlet parts of the trout lamella, which are similar to a diffuser and a nozzle, were modeled. This means that only about $40 \%$ of the length of the lamella was modeled. Up-scaling the lamella geometry 500 times resulted in the following dimensions: inlet and outlet diameters of $10 \mathrm{~mm}$ at the first and last pillars, respectively; model length of $160 \mathrm{~mm}$; model width of $60 \mathrm{~mm}$; and thickness of the lamella channel of $3.5 \mathrm{~mm}$. This model allowed us to perform experimental flow investigations by maintaining the main geometric features of the trout lamellae. The model contained altogether 94 pillar cells which formed a structured mesh. The pillar cells were arranged in 20 rows with a distance of $7.5 \mathrm{~mm}$ between rows and a distance of $7.5 \mathrm{~mm}$ between the pillar cells within each row. Each row was staggered relative to the neighboring rows with a value of $3.75 \mathrm{~mm}$ in a transversal direction (see Fig. 2). The diameter of the pillars was $3.5 \mathrm{~mm}$.

In our experiments we used two simplified blood model test fluids: a one-phase fluid (sun flower oil with a dynamic viscosity of $60 \mathrm{mPa} \cdot \mathrm{s}$ and a density of $0.92 \mathrm{~kg} / \mathrm{l}$ at $20^{\circ} \mathrm{C}$ ) and a so-called two-phase fluid, consisting of sun flower oil and colored water, which formed drops in the oil after injection. The water drops modeled the deformable erythrocytes (red blood cells) and the oil modeled the plasma. The size of the water drops was $3.5 \mathrm{~mm}$ high (filling the lamellar channel) and about $4-5 \mathrm{~mm}$ long. These sizes agree with the scaling factor of 500 . The fluids were pumped by two Perfusor ${ }^{\circledR}$ VII (B.BRAUN, Germany) piston pumps, which can produce a flow between 0.1 and $99.9 \mathrm{ml} / \mathrm{h}$. The 
flow rate chosen was $140 \mathrm{ml} / \mathrm{h}$ in both cases, which was divided into two times $70 \mathrm{ml} / \mathrm{h}$ for the two-phase flow. As a result, the Reynolds number was 0.076 at the inlet. This value corresponds to the physiological values of the fish. According to the literature, the tench has 20 lamellae/mm filament and a total length of all filaments of $3000 \mathrm{~mm}$ [8]. This indicates that the total gill blood flow of $1.5 \mathrm{ml} / \mathrm{s}$ [1] is divided into 60,000 lamellae. A blood viscosity of $4 \mathrm{mPa} \cdot \mathrm{s}$ [9], a density of $1 \mathrm{~g} / \mathrm{cm}^{3}$ and the diameter of the afferent lamellar arteriole of $17 \mu \mathrm{m}$ [4] allows determining the Reynolds number of 0.5. This indicates a Stokes flow and therefore the flow shape is not strongly influenced by changes in the Reynolds number. The use of two pumps provided the possibility of setting the oil-water ratio. The percentage of water within the flow corresponds to the proportion of blood volume that is occupied by red blood cells (hematocrit value). A specially designed injector allowed us to generate water drops in the oil of a defined size. The model, and the two-phase flow through it, can be seen in Fig. 2. The pillar cells, which interact with the colored water drops, are also visible.

The flow in the model was investigated using particle image velocimetry (PIV) [10]. Since the flow in the lamella may be considered a 2D flow, the model was illuminated by a diffuse light source. A standard light sheet illumination was not possible because of the water droplets and the refraction index differences between oil and PVC (wall and pillars). The oil was mixed with light reflecting particles (Vestosint ${ }^{\circledR}$; Degussa AG, diameter $30-50 \mu \mathrm{m}$, density $1.02 \mathrm{~kg} / \mathrm{l}$ ). The motion of these particles was recorded using a high-speed video camera with a resolution of $512 \times 480$ pixels at 250 fps (Fastcam Super 10 K; Roper Scientific Inc., USA). The velocity fields were calculated with the commercial PIV software DaVis 6 (LaVision GmbH, Germany) and then analyzed. Please note that only the velocity of the continuous phase (oil) was measured with this technique.

The images of the two-phase flow were also analyzed in order to assess the local hematocrit value distribution. The model was divided into a structured mesh of regions of interest (ROI), each measuring $5 \mathrm{~mm} \times 5 \mathrm{~mm}$. The images were binary (black and white). Since the colored water was used to simulate erythrocytes, the black areas in the images represented the local fraction of these cells in each ROI. This analysis was done using a script program in the Adobe Photoshop software (Adobe Systems Inc., USA). Masks were generated in order to take into account the pillars and the non-square form of some of the side ROIs.

\section{RESULTS}

The observation of the two-phase flow revealed that the water drops were strongly deformed by the pillar cells as is seen in Fig. 2. In Fig. 3, a one-phase flow (top) and a two-phase flow (bottom) are shown. The flow was $140 \mathrm{ml} / \mathrm{h}$ in both cases, which was divided into two times $70 \mathrm{ml} / \mathrm{h}$ for the two-phase flow. In both pictures, a small amount of dye was injected in the center of the inflow section of the model. This allowed us to visualize the effects of the pillar cells and of the two-phase flow. Only a weak mixing of the dye can be seen in the one-phase flow. The enlargement of the dye filament correlates well with the channel enlargement of the lamella. The thickness of the dye filament at the inlet was about $0.5 \mathrm{~mm}$. In the middle of the model the dye is between $-6 \mathrm{~mm}$ and $+6 \mathrm{~mm}$ thick, and at the outlet the dye filament was only $2.5 \mathrm{~mm}$ in diameter. In the two-phase flow, the mixing was much stronger. The dye was found in the entire cross-section ( $y$ is between $-30 \mathrm{~mm}$ and $+30 \mathrm{~mm}$ ) in the middle of the model and in the outlet part of the model (see Fig. 3).

Particle image velocimetry measurements in the continuous phase (oil) allowed a detailed insight into the flow. In Fig. 4 an example of such a measurement is shown. In Fig. 5, the $x$ - and $y$-components of the velocity, $U$ and $V$, are depicted for different $x$-positions of the one-phase (1P) and the two-phase (2P) flows. The values were extracted from the PIV measurements and were averaged over a cross section for both velocities $U$ and $V$, respectively. Only the first half of the fluid model is depicted. It can be seen that the magnitude of the velocities in the two-phase flow is higher than that for the one-phase 

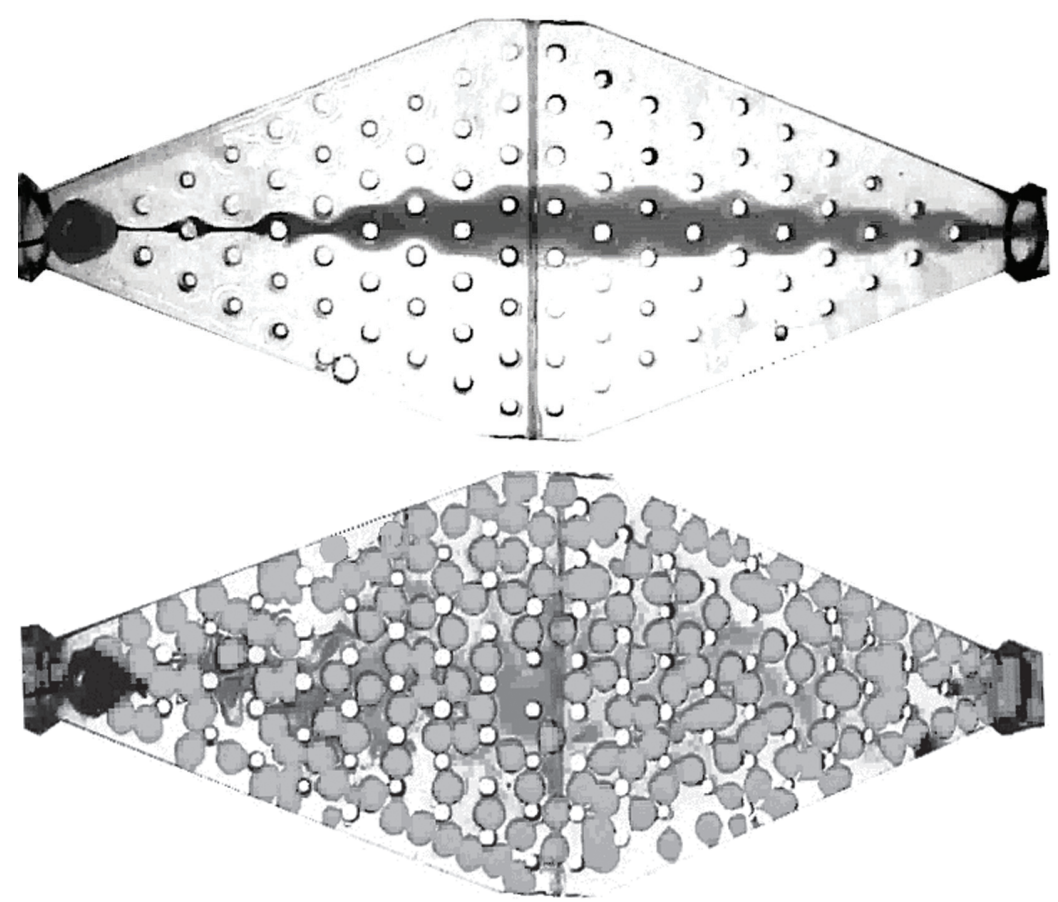

Figure 3: A dye filament was generated at the model inlet in order to show the mass transport in the lamella with a one-phase (top photograph) and a two-phase flow (bottom photograph). The flow is from left to right. The flow rate is $140 \mathrm{ml} / \mathrm{h}$ in both cases. It is divided into two times $70 \mathrm{ml} / \mathrm{h}$ for the two-phase flow.
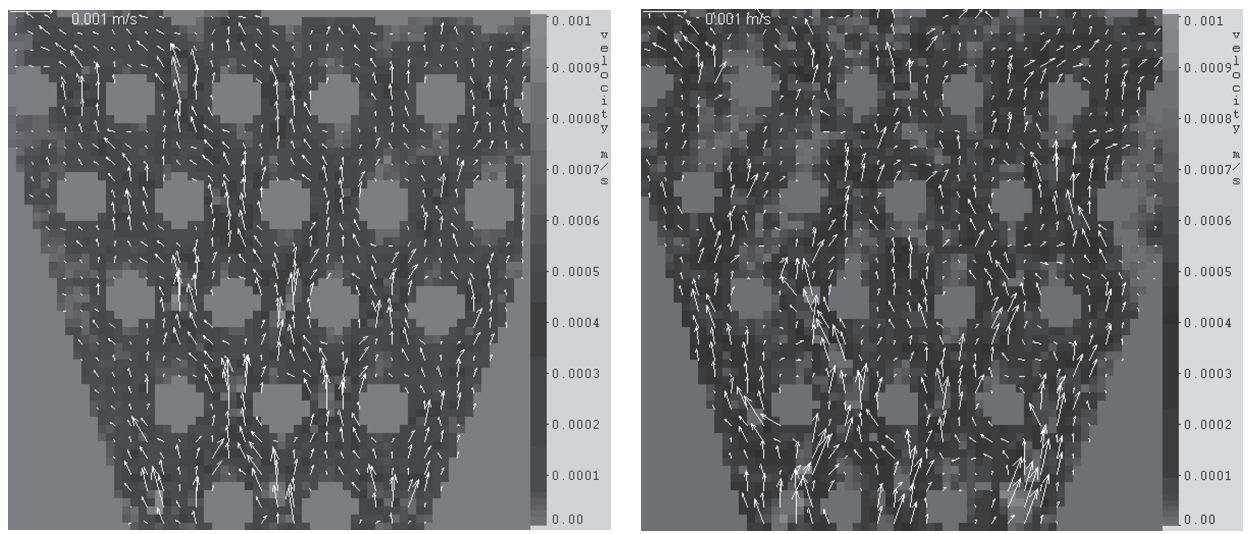

Figure 4: Velocity distribution in the model of a fish gill. Left: one-phase flow with a flow rate of $140 \mathrm{ml} / \mathrm{h}$. Right: two-phase flow with a flow rate of $70 \mathrm{ml} / \mathrm{h}$ per phase. 


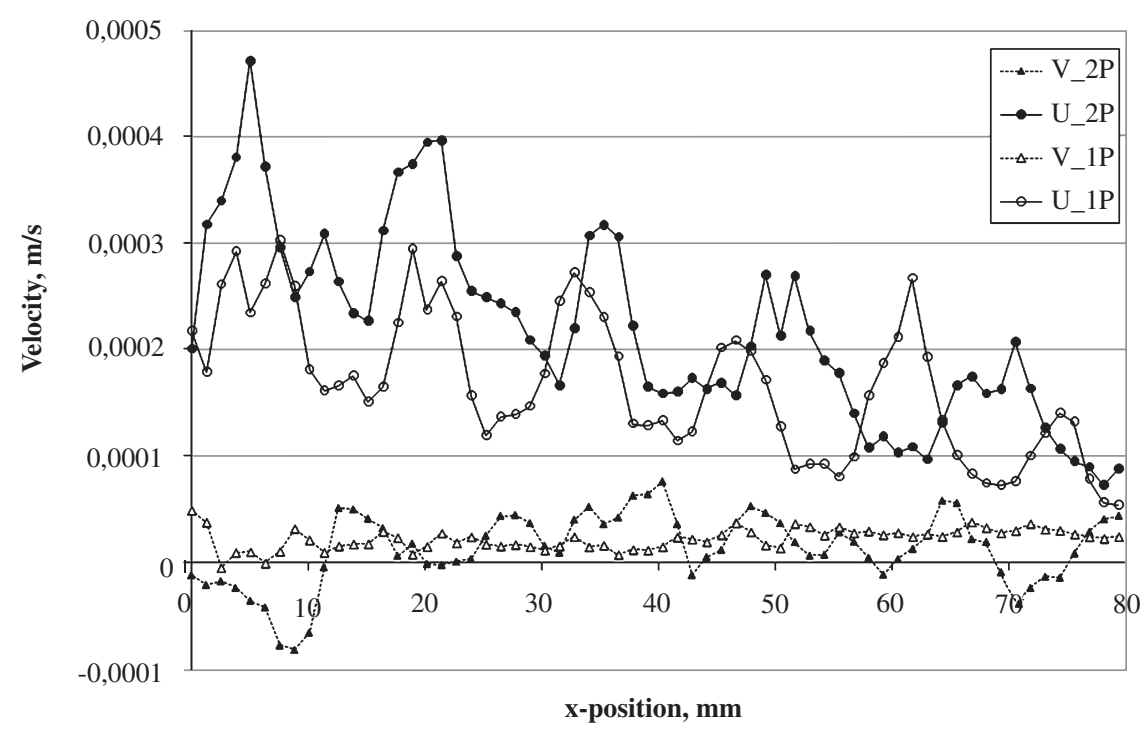

Figure 5: $x$ - and $y$-Components of the velocity averaged over cross sections along the $x$-axis for one-phase (1P) and two-phase (2P) flows. Only the first half of the model is depicted.

flow. As the one-phase flow is symmetric, the values for the velocity in $y$-direction ( $V$-component) are almost zero. The deviation to zero is caused by a small misalignment of the model. Therefore, the mean flow is not perfectly vertical and the $V$-component is not zero. For the two-phase flow, the magnitude of this velocity component does not exceed the velocity in the $x$-direction ( $U$-component) in the middle of the model $(x=80 \mathrm{~mm})$. For the two-phase flow, the velocity in the $x$-direction ( $U$-component) in the middle of the model $(x=80 \mathrm{~mm})$ is in the vicinity of the magnitude of the $V$-component. The flow in the two-phase flow is only symmetric if time averaged. Since the value of the $V$-component is only averaged over a cross section for one instant of time, there is a considerable deviation from zero.

The analysis of the velocity components, averaged over the whole model, shows that the mean $U$-velocity of the one-phase flow is $1.67 \cdot 10^{-4} \mathrm{~m} / \mathrm{s}$ with a standard deviation of $6.61 \cdot 10^{-5} \mathrm{~m} / \mathrm{s}$ and a maximum velocity of $3 \cdot 10^{-4} \mathrm{~m} / \mathrm{s}$. These values for the two-phase flow were $2.2 \cdot 10^{-4}, 9.11 \cdot 10^{-5}$, and $4.8 \cdot 10^{-4} \mathrm{~m} / \mathrm{s}$, respectively. The difference between the averaged velocities for one- and two-phase flows is caused by the fact that the results for the two-phase flow represent only plasma (oil) flow. For the secondary velocity, $V$, the averaged values for the standard deviation and maximum velocity value are $2.25 \cdot 10^{-5}, 0.95 \cdot 10^{-5}$, and $4.92 \cdot 10^{-5} \mathrm{~m} / \mathrm{s}$ for the one-phase flow and $2.97 \cdot 10^{-5}, 2.09 \cdot 10^{-5}$, and $8.17 \cdot 10^{-5} \mathrm{~m} / \mathrm{s}$ for the two-phase flow. These differences mean a significantly higher mixing in the model with a two-phase flow which was shown by the dye filament visualization.

In Fig. 6, the distribution of the $x$-component of the velocity along the $y$-axis can be seen for one-phase and two-phase flows. The top figure shows the distribution for $x=27 \mathrm{~mm}$, the bottom for $x=35 \mathrm{~mm}$. It may be seen that the velocity varies more in the two-phase than in the one-phase flow. In addition, the one-phase flow velocity distribution resembles a parabolic profile. In the two-phase flow the velocity distribution is similar to a plug flow.

The water drop proportion (the equivalent of the local hematocrit distribution) in the model was assessed with image processing tools. The model was divided into ROIs of $5 \mathrm{~mm} \times 5 \mathrm{~mm}$ size and 

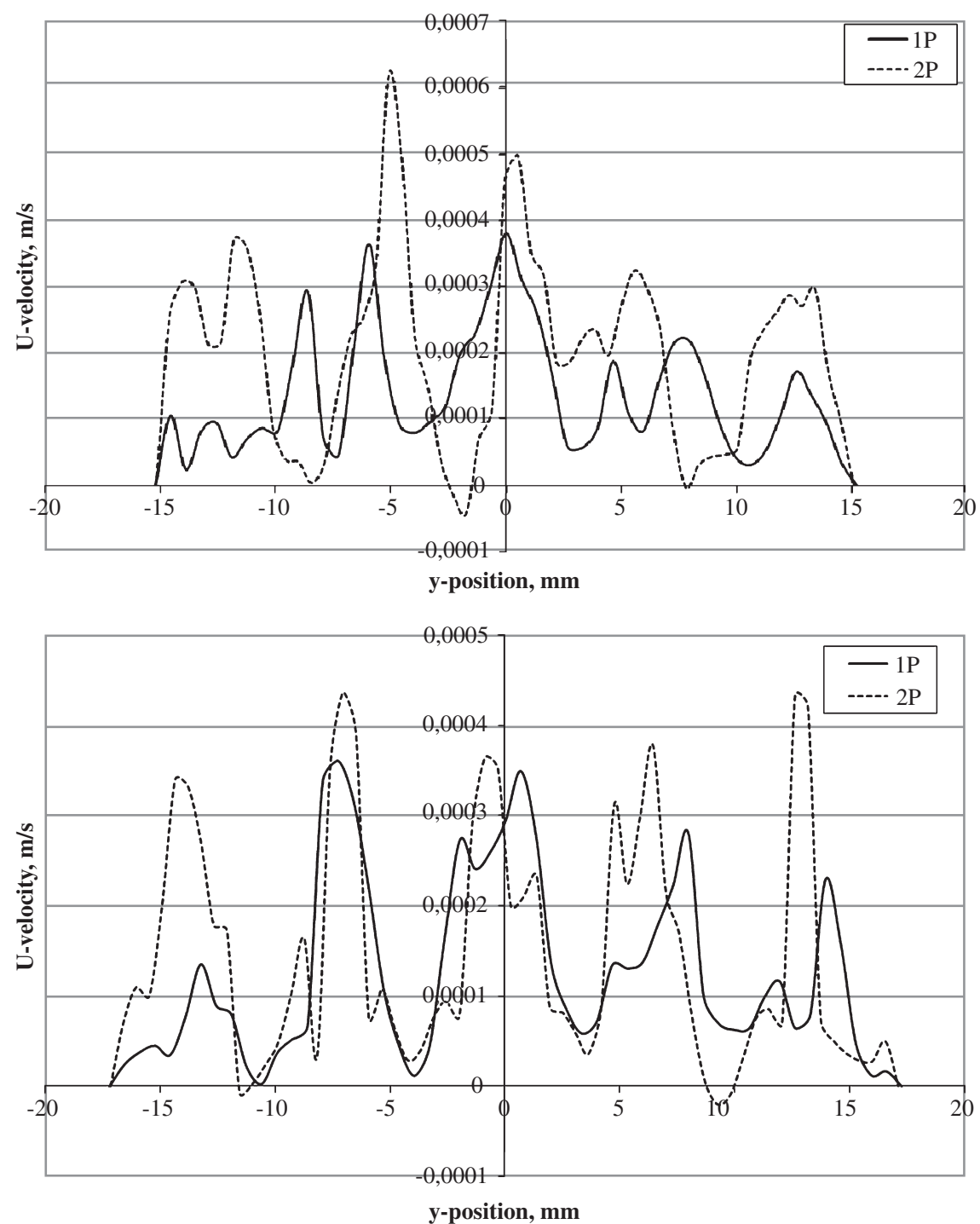

Figure 6: Distribution of the $x$-component of the velocity in the $y$-direction for $x=27 \mathrm{~mm}$ (top) and $x=35 \mathrm{~mm}$ (bottom). Dashed lines show the distribution for the two-phase flow, solid lines for the one-phase flow. The values are not time averaged but show an instantaneous value of the overall steady flow.

the hematocrit value for each segment was averaged over 100 time shots. Figure 7 shows the change in the local hematocrit value along the $x$-axis from the inlet to the outlet of the model. In order to obtain this curve, we averaged the local hematocrit values over all ROIs with the same $x$-coordinate. The mean hematocrit value averaged over the entire model is $53.9 \%$ with a standard deviation of $14.2 \%$. This value correlates well with the defined hematocrit at the inlet $(50 \%)$. Nevertheless, the hematocrit value is not constant in the lamella. At the inlet it reaches $80 \%$, at some of the $x$-positions 


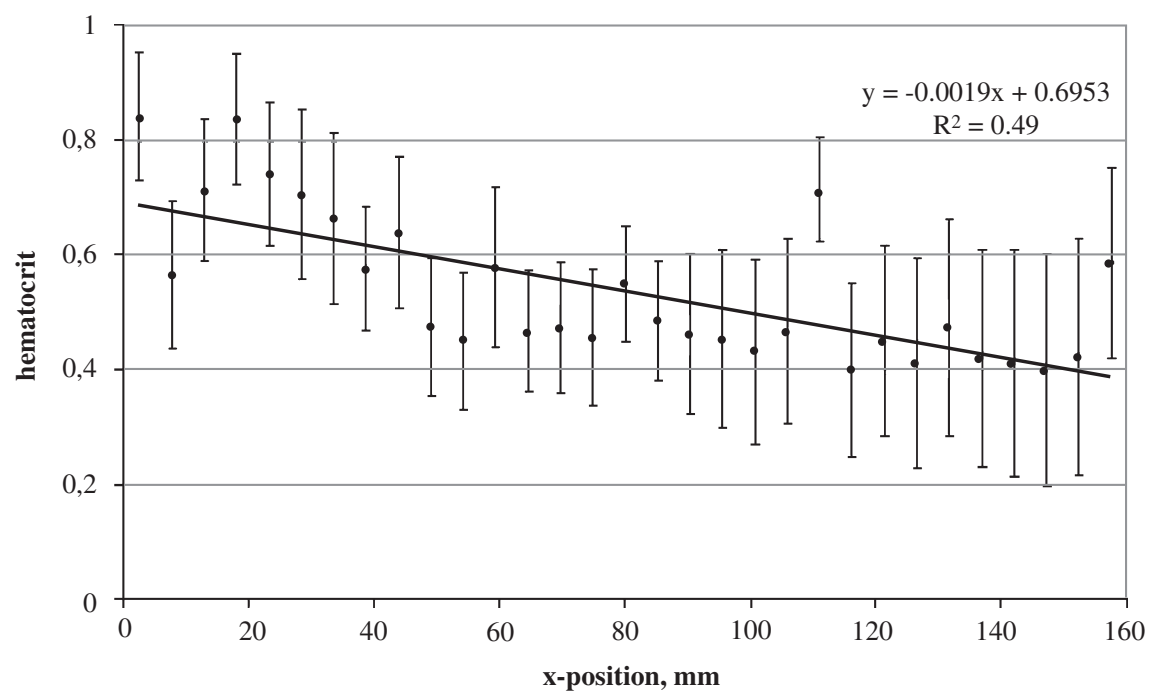

Figure 7: Local hematocrit value distribution along the $x$-axis of the lamella model.

and at the outlet the value is less than $40 \%$ after a more or less linear decrease. At first sight, it might be surprising that the hematocrit values at the inflow and the outflow are different since the flow is steady and therefore the water drops per second must be the same. But the hematocrit value is not defined as particles per volume flow but per volume. A higher hematocrit value in the model than at the inflow means that the oil (the continuous phase) is faster than the water drops in the model. In other words, the motion of the water drops is hindered by the pillars.

\section{DISCUSSION}

The observation and investigation of the flow in the model of a fish gill gave many hints as to why the gas exchange in gills is effective and efficient.

The gas exchange in a gill is enhanced due to a combined effect of erythrocytes and structures similar to a pillar or, in other words, by a two-phase flow. The pillars deform the erythrocytes and impede their motion, consequently influencing the motion of the plasma. As a result, the motion of the plasma is not as uniform as it would be in a pure plasma flow and the transversal exchange is increased. This was confirmed by a dye injection visualization technique and by measured velocity profiles. The deformation of the erythrocytes from a more or less spherical shape into stretched entities causes an increased gas exchange area. Finally, the local hematocrit is increased due to the hindrance of the erythrocytes at the pillars, which again leads to an increase in the gas exchange area. Note that pillars alone do not generate a transverse mixing of the blood. However, even in the one-phase flow the pillars contribute to the more efficient oxygen transport. The cross transport of the oxygen from the wall to the center of the fluid film can only be done by diffusion. The pillar morphology, however, allows a fluid volume which moves along the center between two pillars with a maximum diffusion distance to hit against the wall of the pillar in the next row and as a result to move at least partly along the pillar wall to the upper and lower membrane. This reduces the diffusion distance.

Another aspect is the velocity of the different phases of the two-phase blood flow model. PIV investigations of the first half of the model with $0<x<80 \mathrm{~mm}$ showed that the velocity of the plasma (oil) is greater for a two-phase flow than for a one-phase flow. Since the total flow rate is the same in 
both cases, this means that the velocity of the second phase, the erythrocytes (water drops), is less than that of the plasma. Therefore, the residence time of the water drops is longer than that of the plasma. This means a prolonged time for the gas exchange, which can be an advantage for the fish. This is the reason why the volume hematocrit in the gill model differs from the volume flow hematocrit at the inflow and outflow.

\section{CONCLUSIONS}

Flow measurements in the simplified model of a fish gill were presented. The main aim was to understand the effectiveness and efficiency of the gills as an oxygenator. The results could be helpful when designing mass or heat exchangers.

Future work will include further investigation of the efficiency of the gill, especially the investigation of the low energy consumption on the water side of the gills.

Questions to be answered include the following: Is the exchange enhanced by the surface structure of the gills? Is the 3D morphology of the gills important for water flow and therefore for gas exchange? Other questions involve mass transport on the water side. All of these questions are to be investigated in future studies.

\section{ACKNOWLEDGMENT}

This work was supported by the German Ministry for Education and Research (BMBF).

\section{REFERENCES}

[1] Schmidt-Nielsen, K., Animal Physiology, Cambridge University Press: Cambridge, London, New York, 1975.

[2] Froese, R. \& Pauly, D., eds, Fish Base 2004. Internet publication: www.fishbase.org, Version $(10 / 2004)$.

[3] Medtronic Inc. Internet publication: www.medtronic.com/cardsurgery/arrested_heart/trillium.html, Version 08.07.

[4] Olson, K.R., Vascular anatomy of the fish gill. Journal of Experimental Zoology, 293, pp. 214-231, 2002.

[5] Olson, K.R., Gill circulation: regulation of perfusion distribution and metabolism of regulatory molecules. Journal of Experimental Zoology, 293, pp. 320-335, 2002.

[6] Wilson, J.M. \& Laurent, P., Fish gill morphology: inside out. Journal of Experimental Zoology, 293, pp. 192-213, 2002.

[7] Srivastava, A.K. \& Griffith, R.W., Erythrocyte morphology and the ecology of species of fundulus. Copeia, 1974, pp. 136-141, 1974.

[8] Stevens, E.D., Gill morphometry of the red drum, Sciaenops ocellatus. Fish Physiology and Biochemistry, 10, pp. 169-176, 1992.

[9] Lebelo, S.L., Saunders, D.K. \& Crawford, T.G., Observations on blood viscosity in striped bass, Morone saxatilis (Walbaum) associated with fish hatchery conditions. Transactions of the Kansas Academy of Science, 104, pp. 183-194, 2001.

[10] Adrian, R.J., Particle-imaging techniques for experimental fluid mechanics. Annual Reviews of Fluid Mechanics, 23, pp. 261-304, 1991. 